\title{
Student Engagement With Course Content and Peers in Synchronous Online Discussions
}

\author{
Allison M. Truhlar and M. Todd Walter \\ Department of Biological and Environmental Engineering, Cornell University \\ Kimberly M. Williams \\ Center for Teaching Innovation, Cornell University
}

\begin{abstract}
As higher education institutions in United States offer online courses to growing audiences, there is increasing desire to understand how best to engage students with both course content and their peers. This case study examines the effects of assigning chat roles and facilitating self- and group reflection on student-content and student-student interaction outcomes in four synchronous chats conducted in an online introductory-level sustainability course. We also considered what occurred within group reflections to inform how they are structured in the future. We found that assigning roles increased the proportion of critical student-student interactions. Self-reflections had no effect on either interaction type. Groups completing group reflections had a greater proportion of critical student-content interactions in the third chat and critical student-student interactions in the fourth chat than the groups that did not complete the group reflections. Based on our results, we plan to keep roles and group reflections going forward, and eliminate self-reflections. Furthermore, to increase the effectiveness of the group reflections, we propose some ideas to increase student ability to convert their ideas into change during subsequent chats.
\end{abstract}

Keywords: online debate, roles, reflections, critical thinking, Socratic questioning, student agency

Truhlar, A.M., Williams, K.M., \& Walter, M.T. (2018). Case study: Student engagement with course content and peers in synchronous online discussions. Online Learning, 22(4), 289-312. doi:10.24059/olj.v22i4.1389

\section{Student Engagement With Course Content and Peers in Synchronous Online Discussions}

This case study considers an entirely online introductory-level sustainable development course offered at a research university with an undergraduate enrollment of about 14,000. Synchronous chats held four times over the semester were the primary means by which students engaged with one another and developed a learning community. In spring 2015, enrollment in the course exceeded 300 students, requiring the use of 40 undergraduate teaching assistants (TAs) to facilitate chats (one group per TA) and complete other tasks, such as grading. In fall 2016, 
enrollment was capped at 200 students, and 15 undergraduate TAs were recruited. In both semesters, the first author of this paper served as the instructor and primary coordinator for the undergraduate TAs.

In spring 2015, the instructor had an intuitive sense from reading through chat transcripts that students were not fully engaged. For example, as soon as new questions were posted in a chat, it was common for a rapid series of long responses to follow. The instructor provided questions ahead of time to allow students to prepare, and it seemed possible that students were simply copying and pasting prewritten responses to earn participation points for being present during the chat. This was anecdotally confirmed through conversations with past students. To gain further insight into how students were engaging in the chats, the instructor closely read and qualitatively analyzed a selection of chat transcripts. Two themes relevant to this study emerged: (a) students were not critically engaging with the course information, as evidenced by a majority of postings written at low levels of thinking on Bloom's taxonomy, and (b) students were not critically engaging with information provided by their peers, as evidenced by a lack of challenges to new information.

As a result of these findings, for fall 2016, one intervention was implemented that has been routinely shown to increase both student-content (e.g., Schellens, Van Keer, De Wever, \& Valcke, 2007) and student-student (e.g., Hara, Bonk, \& Angeli, 2000) interactions in asynchronous discussions: assigning discussion roles. The evaluation of the discussion role intervention makes important contributions to our knowledge of designing interventions for synchronous discussions, which are not as thoroughly researched as asynchronous discussions (Martin, Ahlgrim-Delzell, \& Budhrani, 2017). In addition, the effect of self- and group reflections on student-content and student-student interaction was tested, as this is an area that has been identified in the literature for further research (De Wever, Schellens, Van Keer, \& Valcke, 2008; Murphy \& Jerome, 2005; Walker, 2004). This case study reports on the literature we used to inform these changes, the observed results, and our suggestions for future synchronous discussions in this and similar courses.

\section{Review of Related Literature}

\section{Pedagogy to Promote Interaction in Online Learning}

The United States Distance Learning Association has indicated that interaction is an integral component of quality distance education, including online education (Holden \& Westfall, 2007). In any educational context, interaction falls into one of three categories: student-instructor, student-student, or student-content (Moore, 1989). A meta-analysis of 74 studies found that implementing at least one type of interaction intervention in distance education courses increased student understanding of course content (Bernard et al., 2009). Among the three interaction types, student-student and student-content interactions had significantly greater effect sizes on student learning.

In online courses, the majority of student-student interactions take place in asynchronous discussions (e.g., discussion forums students can access on their own time) or synchronous discussions (e.g., live chat rooms) carried out over a virtual platform (Bernard et al., 2009). Aside from course readings and assignments, discussions are also where many student-content interactions occur (Ertmer, Sadaf, \& Ertmer, 2011). Therefore, there is great interest in 
understanding how to best encourage and support interactions in these discussion formats. Over the past two decades many interventions have been studied for their ability to improve outcomes of student interactions in online discussions. Examples include assigning roles to students (Wise, Saghafian, \& Padmanabhan, 2012) and asking students to reflect on their contributions to the discussion (Kayler \& Weller, 2007).

Discussion roles. Assigning discussion roles to students has been suggested to have many benefits, including increasing student participation (Tagg, 1994), interaction (Hara et al., 2000), and knowledge integration and construction (Schellens, 2005; Schellens et al., 2007; Strijbos, Martens, Jochems, \& Broers, 2007). However, the research on whether these outcomes are actually achieved is inconclusive. Wise et al. (2012) suggested that this is because research has focused on roles, but not on the actual functions the roles perform in conversation. Therefore, depending on how the instructor or researcher specifies the role to students, roles with the same name could be asked to fulfill different functions, or vice versa. Wise et al. (2012) identified the three most helpful functions common to the roles assigned in 12 studies - namely, (a) give direction, (b) summarize, and (c) provide critical response. The "give direction" function is typically assigned to the student expected to start the conversation and can be expanded to include keeping the conversation on topic for its duration (Hara et al., 2000; Persell, 2004; Tagg, 1994; Wise et al., 2012; Zhu, 1998). The "summarize" function asks students to synthesize what has been stated in the discussion up to a certain point, usually set at the end of the discussion period. Posts made by students assigned this function are consistently associated with higher levels of thinking due to the synthesis required by the function description itself (De Wever, Van Keer, Schellens, \& Valcke, 2007; Schellens, 2005). Summary posts have also been shown to stimulate higher order responses from other students (Wise \& Chiu, 2011). The "critical response" function is defined as "the right to be critical of ideas in the discussion" (Wise et al., 2012). A lack of critical comments on other students' thinking is common to online discussions (De Wever et al., 2008; Schellens, 2005; Schellens et al., 2007). Assigning the critical response function gives students permission to challenge their peers, which they might otherwise avoid (Wise et al., 2012).

Self- and group reflections. Both individual and group reflections are commonly used pedagogical tools to promote better group work (Gibbs, 1994). However, there are few instances of these techniques being applied to online discussions, even though this specific type of group work has the unique quality of producing a written transcript. Multiple researchers have suggested that the reflective reading of transcripts as an intervention to improve students' online discussion strategies is an area that needs more investigation (De Wever et al., 2008; Murphy \& Jerome, 2005; Walker, 2004). Qualitative work has found that structured, written self-reflection on contributions to an online discussion can allow students to identify their strengths and areas for improvement (Kayler \& Weller, 2007; Murphy \& Jerome, 2005). However, whether students have the knowledge and skill set required to be self-reflective is an important consideration for the success of a self-reflection intervention. In one quantitative study, undergraduate students assigned to complete self-reflections for online asynchronous discussions did not demonstrate an increase in knowledge construction compared to students who did not complete self-reflections (De Wever et al., 2008). Unlike the graduate students studied by Kayler and Weller (2007), undergraduates may not be able to accurately self-assess the extent of their knowledge construction (De Wever et al., 2008). 


\section{Measuring Critical Interactions}

As noted by Ertmer et al. (2011), measuring interactions in online discussions comes with challenges. Specifically, not every post is meaningful and relevant to course content (Ertmer et al., 2011). Likewise, many student-to-student posts might be social interactions and not active discussions of course content. Therefore, purely quantitative measures of interaction (e.g., post counts) have not been as useful as those mixed with qualitative measures (e.g., post quality), often defined in terms of critical thinking (Ertmer et al., 2011; Walker, 2004; Wise \& Chiu, 2011). For the remainder of this manuscript, "critical interaction" will be considered, as opposed to all student-content or student-student interaction.

Bloom's original taxonomy (Bloom, Engelhart, Furst, Hill, \& Krathwohl, 1956) is often applied to measuring critical thinking about course content. The higher levels of Bloom's original taxonomy (i.e., analysis, synthesis, and evaluation) correspond to the cognitive processes associated with critical thinking (Pear, Crone-Todd, Wirth, \& Simister, 2001). For student-student interactions, critical thinking occurs when participants hold ideas "publicly accountable" and work to reason out their understanding of those ideas (Mercer, Wegerif, \& Dawes, 1999). This is opposed to a discussion where participants reflexively agree or disagree, and thereby only superficially engage with the ideas put forward. Indicators of critical thinking in a conversation are questions that elicit further explanation of a provided fact or opinion, questions that require a defense of a line of argument, and statements containing a counter or alternative argument (Walker, 2004). These question types are labeled by Walker (2004) as "probe," "challenge," and "counter" questions, respectively.

\section{Online Pedagogy in Context}

So far, we have considered how specific pedagogical strategies-namely, discussion roles and reflections - can affect student interactions in online courses and how to measure these effects. However, these learning processes and outcomes interact dynamically with at least two other components in the online classroom: the logistical constraints and advantages of the online learning platform, and the agency of individual students and groups of students (Basharina, 2009). As Basharina (2009) notes, it is critical to consider these additional contextual factors in order to avoid the possible pitfall of ascribing failure to achieve learning outcomes on the student response to the pedagogical strategies alone.

Logistical constraints that have been identified for asynchronous discussions, and which also apply in the synchronous context, include missed or misinterpreted communication (Ware, 2005), feeling overwhelmed by the volume of communication that occurs in online settings (Basharina, 2009; Sengupta, 2001), and technical problems (Basharina, 2009). Additionally, the tool itself can be both a source of constraints and opportunities, depending on its design and supported functions. A recent review of online synchronous discussions found the choice of tool to be the most common independent variable in study designs (Martin et al., 2017), demonstrating at least the perceived importance of differences between tools in the online learning literature.

Agency can be defined as "feeling enabled and empowered to act" and solve problems (Kayler \& Weller, 2007). Students react more positively to online courses when they have some power over what they choose to learn-for example, when they are allowed to select learning modules from a menu of choices (Lindgren \& McDaniel, 2012). Pedagogical tools like selfreflections can also be used to promote feelings of agency. Kayler and Weller (2007) found that students who favored written reflection in their learning style were particularly empowered by 
self-reflections and used them to determine how they could continue to improve their own contributions even when they were not happy with their discussion group as a whole. However, students who did not favor written reflection as a learning tool tended to blame bad group discussion experiences on perceived deficiencies in the participation of their groupmates. Therefore, one of the outcomes of this study was the modification of the self-reflection activity to accommodate diverse learning styles with the inclusion of an in-person group reflection.

\section{Research Questions}

This case study examines the effects of assigning chat roles and facilitating self- and group reflection on student-content and student-student interaction outcomes for an online synchronous chat. The main hypotheses addressed in this study are the following: (a) assigning chat roles will increase the proportion of chat posts that contain critical student-content and student-student interactions; (b) self-reflections will further increase the proportion of chat posts containing critical student-content and student-student interactions compared to roles alone; (c) when roles are assigned, groups completing group reflections will have a greater proportion of chat posts containing critical student-content and student-student interactions compared to groups completing only self-reflections; and (d) when roles are removed, groups completing group reflections will have a greater proportion of critical student-content and student-student interactions than groups without group reflections. In addition to these four hypotheses, and in an effort to inform the development of future group-reflection assignments, we ask the following question: What happens during an online, asynchronous, group-reflection process?

\section{Methods}

Both quantitative and qualitative methods were used in this study, to achieve different purposes. Quantitative methods were used to test our four hypotheses, which are informed by existing theory and have measurable variables (Sogunro, 2002). Briefly, a set of three interventions - discussion roles, self-reflections, and group reflections-were designed and implemented over the course of four chats in one semester. Chat transcripts were coded for critical student-content interactions, using the higher levels of thinking from Bloom's original taxonomy (e.g., analysis, synthesis, evaluation) as a proxy. The transcripts were also coded for critical student-student interactions using three types of questions (probe, challenge, or counter) suggested by Walker (2004) as a proxy. The dependent variables of proportion of critical student-content and student-student interactions were then compared through $t$-tests to determine the effect of the three interventions.

Qualitative methods were used to explore what transpires in asynchronous group reflections; numbers would have little meaning in this context until a greater understanding of what to even look for was gained (Sogunro, 2002). Due to the lack of existing research in this topic (e.g., Walker, 2004), we followed grounded theory to allow themes to emerge from the transcripts (Gibbs, 2012). These themes were then used to code the transcripts in subsequent readings.

This study was granted exemption from IRB review. 


\section{Setting}

The course considered in this case study is an introductory sustainability science course taught at a large research university. A total of 180 students enrolled in the fall 2016 semester, with class year ranging from sophomores to seniors. Fifteen undergraduate students who had taken the course previously served as teaching assistants (TAs) and conducted the online discussions. Students were assigned alphabetically to discussion groups. The number of students in a group ranged from eight to 13. All discussions were based around a one-hour informal debate structure.

\section{Interventions}

The selection of interventions for the fall 2016 semester was guided by the emergent themes from the earlier qualitative analysis and the existing literature. A timeline of the interventions is shown in Figure 1. As the first intervention, before the first chat each student was randomly assigned one of three specific roles to focus on during the debate. In brief, the three roles were the Traffic Director, who was responsible for keeping the discussion on topic, the Questioner, who was responsible for asking critical questions of their peers, and the Synthesizer, who was responsible for identifying themes in the discussion and highlighting topics that still needed to be addressed. Within a group, students were distributed evenly between these three roles; if the number of students in the group was not divisible by three, extra students were assigned to the Questioner and Synthesizer roles. Students were assigned roles for Chats 1, 2, and 3, and changed roles each time.

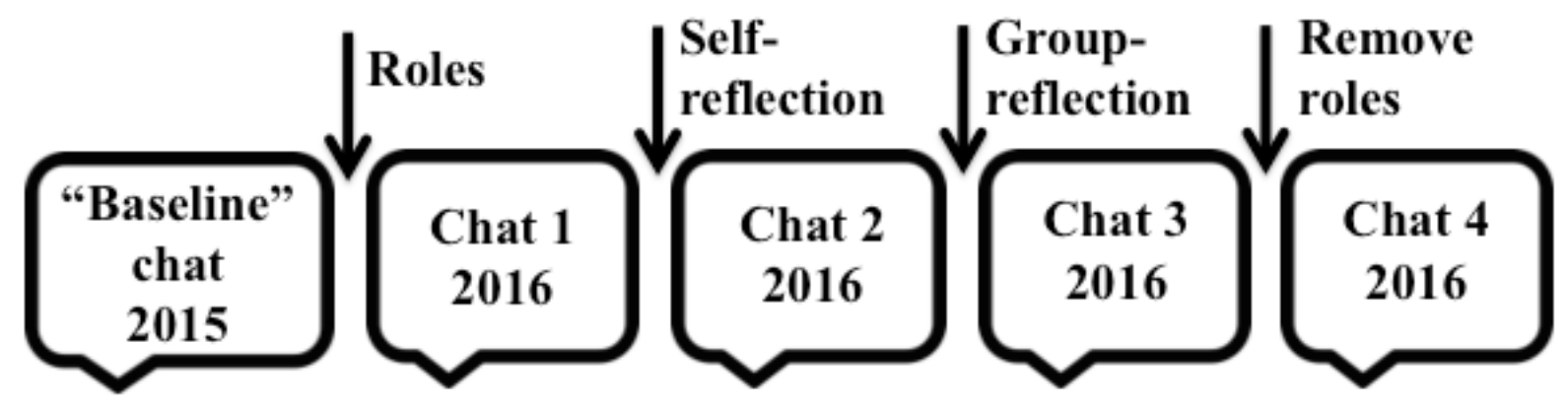

Figure 1. Timeline of interventions used in the online chats. Once an intervention was introduced, it was continued for the rest of the semester, unless otherwise noted.

Following the first chat, students were asked to complete a self-reflection on how they fulfilled their assigned role, drawing on examples of things they did well and things they could improve on from the chat transcript. To ensure their familiarity with all three roles, they were also asked to reflect on examples from the two roles they were not assigned (see Appendix A).

The second chat followed the same procedure as the first, but after the chat eight of the 16 groups were randomly selected to complete both an abbreviated version of the written selfreflection (Appendix B) and an asynchronous group reflection (Appendix C) on what went well in the chat and what could be improved. The remaining eight groups were assigned to complete a written self-reflection only and to complete an asynchronous group discussion activity that was an extension of the topical discussion in the synchronous chats. This discussion activity did not 
include a reflection component and was included as a control against any possible effects of having additional group interaction time.

The third chat followed the same procedure as the second chat. The fourth chat followed the same procedure as the second and third chats, except students were not assigned chat roles. Table 1 summarizes the interventions used in each chat and how they relate to our four hypotheses.

\section{Table 1}

Interventions Applied in Each of the Four Chats, With the Corresponding Hypotheses and t-Test Results.

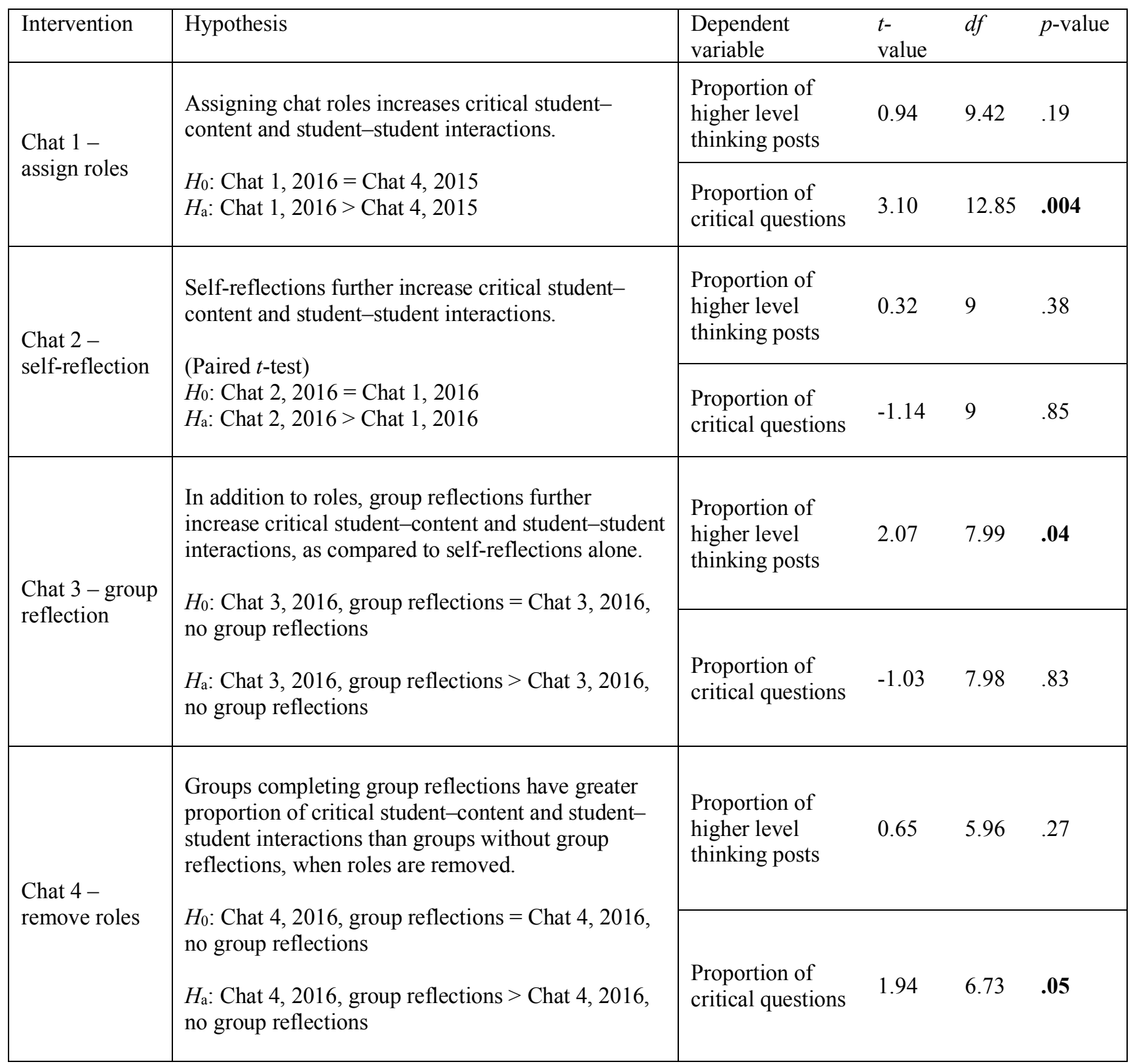

Note. Bolded $p$-values indicate a significant result at the $95 \%$ confidence level. 


\section{Measuring Student-Content and Student-Student Interactions}

At the beginning of the fall 2016 semester, students provided consent to have their chat transcripts included in this analysis. Groups containing students who did not provide consent were eliminated from consideration; this left 10 groups for our analysis, evenly divided between the group-reflection and no-group-reflection conditions.

The first 40 posts in five chat transcripts from the last chat in 2015 and 10 chat transcripts from 2016 chats were coded for critical student-content interactions, using the three highest levels in a version of Bloom's original taxonomy, modified to include "opinion as the lowest level of thinking, as a proxy" (Bradley, Thom, Hayes, \& Hay, 2008, Table 2). If a post included multiple statements, it was coded according to the highest level of thought it contained. The transcripts were also coded for critical student-student interactions using the three types of questions (probe, challenge, or counter) suggested by Walker (2004) as a proxy. A proportion of both critical student-content interactions and critical student-student interactions out of the 40 total posts analyzed within a transcript were calculated. These proportions were used as the dependent variables in one-sided $t$-tests used to explore each hypothesis; see Table 1 for a full description of the hypotheses and corresponding $t$-tests used. All statistical analyses were performed with $\mathrm{R}$ version 3.2.3 (R Core Team, 2015).

Table 2

Modified Version of Bloom's Original Taxonomy

\begin{tabular}{ll}
\hline Level & Example \\
\hline Opinion & $\begin{array}{l}\text { "I think..." with no } \\
\text { "because" }\end{array}$ \\
\hline Knowledge & Cite reading \\
\hline Understanding & Paraphrase reading \\
\hline Application & Relate to own experience \\
\hline Analysis & Compare information \\
\hline Synthesis & Draw connections \\
\hline Evaluation & Justify position \\
\hline
\end{tabular}

Note. Adapted from "Ask and You Will Receive: How Question Type Influences Quantity and Quality of Online Discussions," by M. E. Bradley, L. R. Thom, J. Hayes, and C. Hay, 2008, British Journal of Educational Technology, 39(5), 888-900.

\section{Qualitative Analysis}

In order to understand what was happening in the group reflections, we coded transcripts from three of the five groups participating. These groups, arbitrarily named A, B, and C, were selected because they had the same students participating in each chat. Following grounded theory, 
we allowed themes to emerge from the transcripts in the initial reading (Gibbs, 2012). These themes were the following: logistical changes suggested for future discussions, level of agency expressed over discussion outcomes, and ability to suggest concrete changes for future discussions. We then reread the transcripts, looking for evidence of each theme in individual posts and labeling them accordingly. The number of times a theme was mentioned was tabulated.

\section{Quantitative Results}

\section{Results}

Hypothesis 1. Compared to a chat with no roles assigned, chats with assigned roles had a greater proportion of critical student-content interactions, as evinced by higher level thinking on Bloom's original taxonomy, and student-student interactions, as evinced by critical questioning; $t(9.42)=0.94, p=.19$ and $t(12.85)=3.10, p=.004$, respectively (see Table 1 and Figure 2). However, in the one-sided $t$-test comparison, only the increase in the proportion of critical studentstudent interactions was significant.

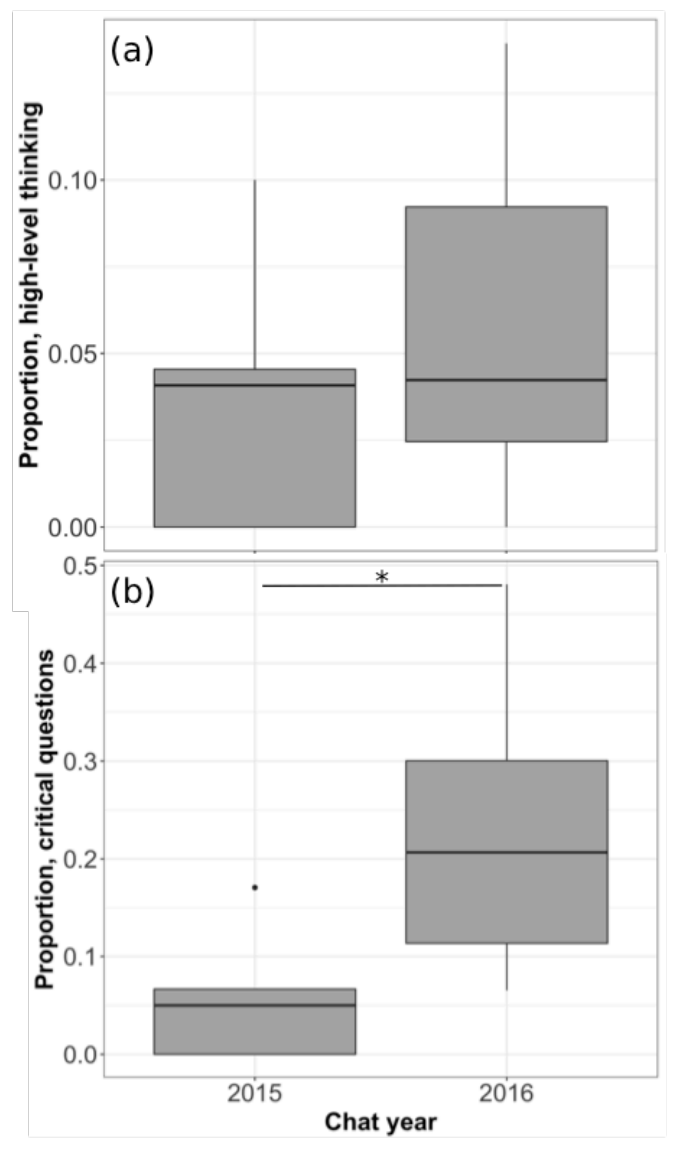

Figure 2. Proportion of total posts in the 2015 chat and Chat 1, 2016 that were coded as being (a) higher level thinking, a proxy for critical student-content interactions, and (b) critical questions, a proxy for critical student-student interactions. Between 2015 and 2016, chat roles were introduced. The upper whisker extends to the largest observed value within the third quartile plus 1.5 times the interquartile range. The lower whisker extends to the smallest observed value within the first quartile minus 1.5 times the interquartile range. An asterisk indicates a significant difference at a 95\% confidence level. 
Hypothesis 2. The addition of self-reflections to the chat format did not increase either the proportion of critical student-content interactions, as evinced by higher level thinking on Bloom's original taxonomy, or the proportion of critical student-student interactions, as evinced by critical questioning; $t(9)=0.32, p=.38$ and $t(9)=-1.14, p=.85$, respectively (see Table 1 and Figure 3 ).

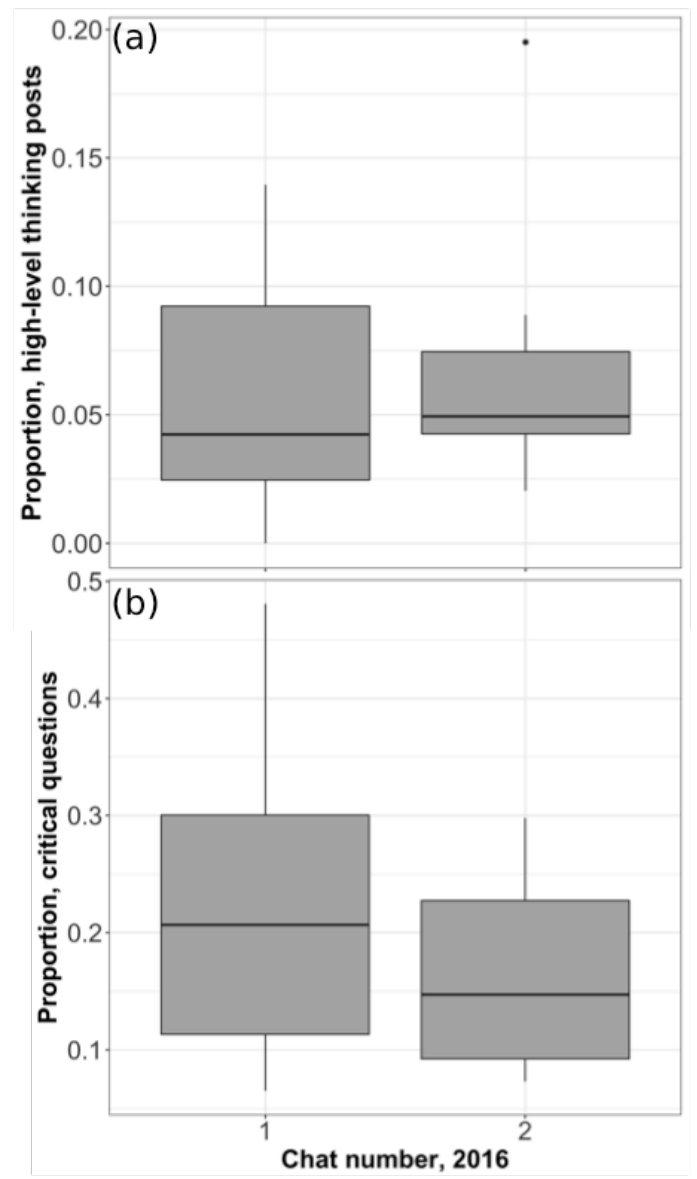

Figure 3. Proportion of total posts in Chat 1, 2016 and Chat 2, 2016 that were coded as being (a) higher level thinking, a proxy for critical student-content interactions, and (b) critical questions, a proxy for critical student-student interactions. Between Chat 1 and Chat 2, self-reflections were introduced. The upper and lower whiskers are drawn as described in Figure 1.

Hypothesis 3. The proportion of critical student-content interactions was significantly greater for groups completing group reflections, compared to groups that did not complete group reflections; $t(7.99)=2.07, p=.04$ (see Table 1 and Figure 4). There was no difference in the proportion of critical student-student interactions between groups in the two treatments; $t(7.98)=$ $-1.03, p=.83$ (see Table 1 and Figure 4 ). 


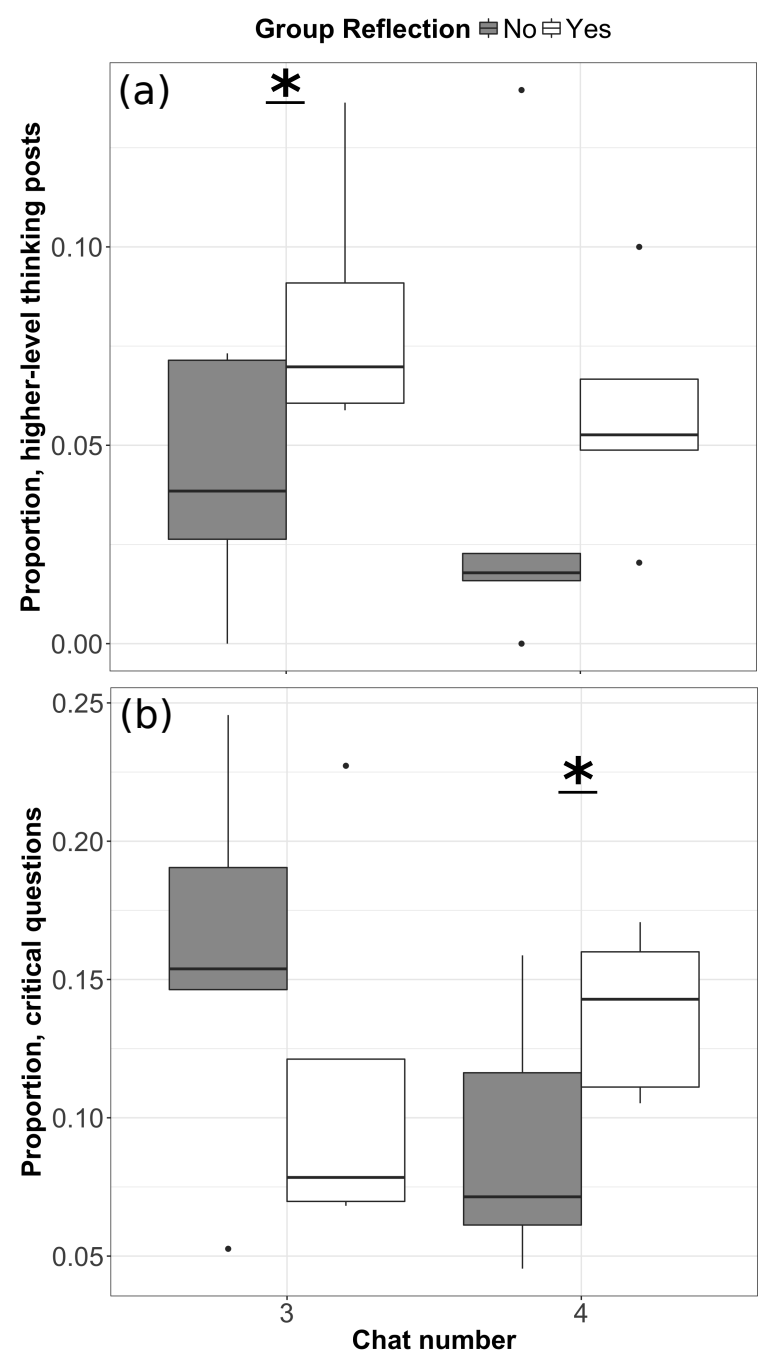

Figure 4. The proportion of posts coded as being (a) higher level thinking, a proxy for critical student-content interactions, and (b) critical questions, a proxy for critical student-student interactions, separated by whether the group completed a group reflection. An asterisk indicates significance at a $95 \%$ confidence level. Lighter shading is used for groups that completed group reflections before Chats 3 and 4, while darker shading is used for groups that did not complete group reflections. The upper and lower whiskers are drawn as described in Figure 1.

Hypothesis 4. When roles were removed for the fourth chat, the groups that completed a group reflection had a greater proportion of critical student-content interactions than groups that did not complete a group reflection, although this difference was not significant in a paired $t$-test; $t(5.96)=0.65, p=.27$ (see Table 1 and Figure 4). In general, the groups completing group reflections maintained higher level thinking in the chats over the course of the semester (see Figure 4). Furthermore, groups completing group reflections had a greater proportion of critical studentstudent interactions in the fourth chat than groups that did not complete the group reflection; $t(6.73)$ $=1.94, p=.05($ see Table 1$)$. 


\section{Qualitative Results}

Three major themes arose around the group-reflection process. First, as a whole, groups tended to favor suggesting logistical changes to the chats over learning-outcome-related changes. Second, among the three groups analyzed, each group differed in the amount of perceived agency (as defined and discussed below) they expressed about their chat experience. Third, each group varied in their ability to suggest concrete changes to the chat. All the above themes held true both with and without role assignment.

Mixed focus on logistics and learning outcomes. In general, groups identified logistical aspects of the chat as being the most ineffective, as opposed to aspects related to achieving target pedagogical outcomes (see Table 3).

\section{Table 3}

Chat Aspect Most Frequently Identified by Each Group as "Ineffective" for the First and Second Group Reflections

\begin{tabular}{|c|c|c|c|c|}
\hline Group & $\begin{array}{l}\text { Reflection } \\
\text { number }\end{array}$ & General category & Specific description & $\begin{array}{l}\text { Number of } \\
\text { distinct posts }\end{array}$ \\
\hline \multirow[t]{2}{*}{ A } & 1 & Logistics & $\begin{array}{l}\text { Multiple conversations occurring } \\
\text { simultaneously }\end{array}$ & 46 \\
\hline & 2 & Logistics & $\begin{array}{l}\text { Schedule of the debate, } \\
\text { specifically the order and timing of } \\
\text { when main points should be } \\
\text { presented and discussed }\end{array}$ & 25 \\
\hline \multirow[t]{2}{*}{ B } & 1 & Logistics & $\begin{array}{l}\text { Schedule of the debate, } \\
\text { specifically the "for" team } \\
\text { received more time to present their } \\
\text { arguments }\end{array}$ & 19 \\
\hline & 2 & Outcomes/Logistics & $\begin{array}{l}\text { Questions were left unanswered, } \\
\text { but it is unclear whether concern } \\
\text { about this was driven more by lack } \\
\text { of information from peers } \\
\text { (outcomes) or by multiple } \\
\text { conversations happening at once } \\
\text { (logistics) }\end{array}$ & 19 \\
\hline \multirow[t]{2}{*}{$\mathrm{C}$} & 1 & Outcomes & $\begin{array}{l}\text { The debate lost focus due to } \\
\text { students getting too bogged down } \\
\text { in "specifics"-for example, } \\
\text { specific definitions }\end{array}$ & 19 \\
\hline & 2 & Logistics & $\begin{array}{l}\text { Multiple conversations occurring } \\
\text { simultaneously }\end{array}$ & 9 \\
\hline
\end{tabular}


Agency. One group, Group A, demonstrated more agency in both the first and second group reflection compared to the other groups (see Figure 5). When members of Group A discussed aspects of the chat they thought were least effective, they tended to emphasize what they could do, or had already done, to effect change (see Example 1). Many also put forth a narrative that they were learning and improving with each chat (see Example 1). Contrary to these patterns, members from Groups B and C expressed the feeling that the ability to change what was happening in the chat was out of their hands, placing responsibility on inadequacies in the chat platform, other students, or the teaching assistant facilitating the discussion (see Example 2):

Example 1: "The most effective thing about our group's chat was the organization and smooth manner it was carried out [in] because we had discussed it beforehand. After having two chats, we knew how out of hand it can get. So we went subject by subject by first tackling one point, then another, and then the last one."

Example 2: "I think that the digital format of the chat is responsible for the constraint on timely responses..."

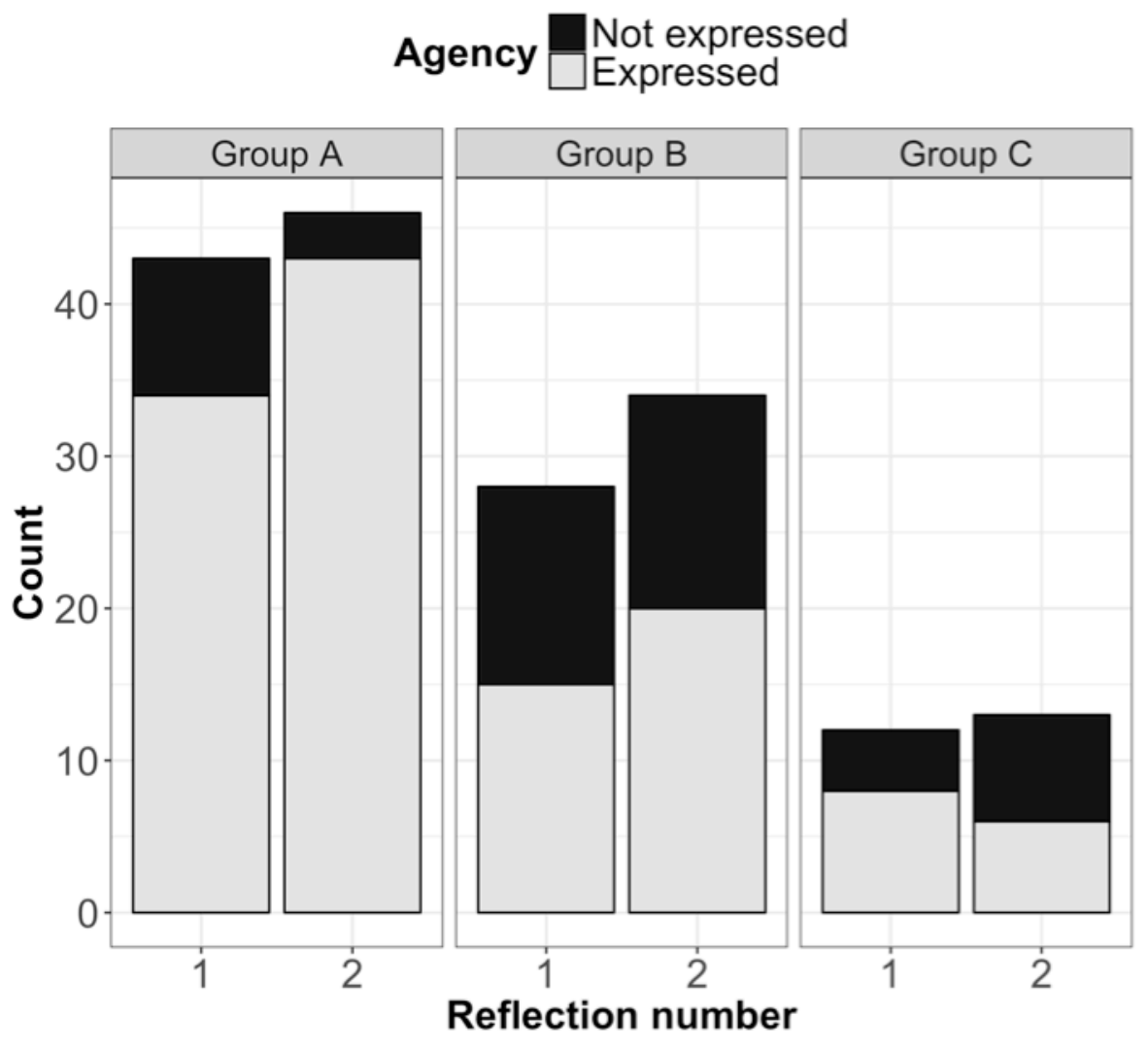

Figure 5. The number of individual posts from the two group reflections, before Chats 3 and 4, respectively, in which students either expressed or did not express agency.

Concrete versus vague suggestions for improvement. Members of Group A consistently proposed concrete actions they could take to improve ineffective aspects of the chat (see Figure 6 and Example 3). In the other two groups, members often did not propose actions to address 
ineffective aspects of the chat. When they did, these suggestions were vague, as indicated by the frequent use of words like "hopefully" and "maybe" (see Example 4):

Example 3: "I agree with you that the fast-paced nature of the debate is probably the main issue. We should definitely utilize the Raise Hand function."

Example 4: "Hopefully next time, all questions will be answered or at least expanded on."

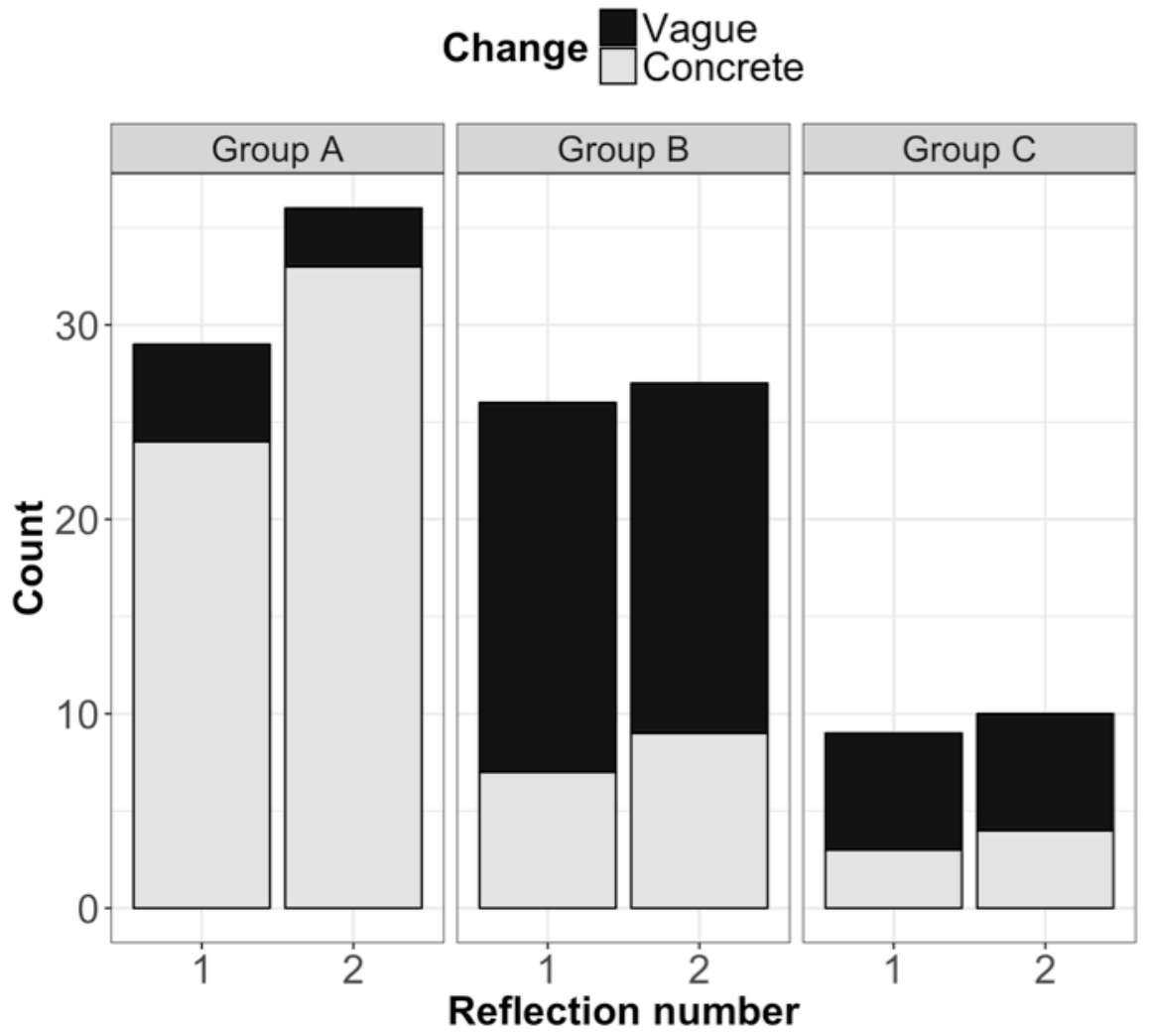

Figure 6. The number of individual posts from the two group reflections, before Chats 3 and 4, respectively, in which students suggested a concrete or a vague change to the next chat.

\section{Discussion}

Assigned roles and group reflections emerged as the most useful interventions for achieving our pedagogical goals of critical student-content and student-student interactions in the synchronous online chats. Specifically, roles significantly increased student-student interaction, while the group-reflections served to maintain higher level thought throughout the semester, even when roles were removed for the final chat. Group reflections also resulted in significantly more student-student interactions when roles were removed. The third intervention we tested, selfreflections, did not result in gains in either higher level thought or student interaction. All results must be considered within the context of this case study-specifically, that the first author and instructor of this course conducted the analysis. This has the advantage of the instructor knowing the desired learning outcomes for the course but creates potential bias toward this individual perspective and course setting. 


\section{Roles}

Our results are in line with previous work that demonstrates that roles increase studentstudent interaction in online chats (Hara et al., 2000). Of the posts directed to another student in Chat 1, 2016 and the 2015 chat, an average of 59\% and 24\%, respectively, were content-based questions. This increase in questioning suggests much of the student interaction in the 2016 chat was driven by the Questioner role. There is qualitative evidence that other roles, specifically the Traffic Director role, increased student-to-student posts as well. In Example 5, Teammates A and $\mathrm{C}$ are the Traffic Directors:

Example 5: Teammate A (Traffic Director): Any thoughts on this Teammate B?

Teammate C (Traffic Director): I can address Student X's question.

Teammate C (Traffic Director): And then Teammate D idk [I don't know] if you want to address Student Y's?

In these exchanges, the Traffic Director posts did not include information relevant to the chat content but rather were intended to organize group members to respond to questions. No organization by students in preparation to answer questions was seen in the 2015 chat, which lacked roles.

Roles did not increase the proportion of posts made at higher levels of thinking. Two roles, the Synthesizer and the Questioner, were specifically implemented due to previous work demonstrating that the functions contained within these roles cause an increase in both critical student-content and student-student interactions (De Wever et al., 2007; Schellens, 2005; Wise \& Chiu, 2011; Wise et al., 2012). A couple of observations might explain the failure of these roles to increase higher level thought in our case. First, we found students in the Synthesizer role emphasized the "summarize" function found in the role description and would provide short restatements of the main points made throughout the debate rather than connecting points and identifying areas yet to be explored. These summaries were explicitly mentioned as being useful in the group reflections, due to the fast-paced nature of the synchronous chat (see Example 6):

Example 6: "It is nice to have the synthesizers to summarize what is going on so that if someone does have a really long response that it can be summarized and easily understood."

Second, of the questions asked across all groups in Chat 1, 83 were posed at lower levels of thinking ("know" or "understand" on Bloom's original taxonomy), while 45 were posed at higher levels of thinking. Notably, no questions were coded as "counter" questions during Chat 1.

Combined, our observations regarding the implementation of the Synthesizer and Questioner roles suggest that our students tended to pick and choose the functions they found most advantageous or expedient within a role definition. In the case of the Synthesizer role, it seems that students found summaries better served their immediate needs due to the fast-paced nature of the synchronous chat, where keeping up with information is the primary challenge, and the synthesis of information becomes a secondary concern. For the Questioner role, although students were given three categories of questions to ask, they neglected to ask any counterquestions, which were intended to fulfill the critique function described by Wise et al. (2012). Therefore, in both of these roles, students effectively selected the functions of the role that favor lower level thinking. 


\section{Self-Reflections}

After the addition of self-reflections before the second chat, the proportion of neither critical student-content nor student-student interactions increased. In reading the reflections, we did find that students, as instructed by the self-reflection prompt, considered whether each role was properly executed in Chat 1 and how the roles could be better fulfilled in Chat 2. This is similar to the qualitative results from previous work that found that self-reflections caused students to "identify patterns of participation which could enhance the larger learning community" (Kayler \& Weller, 2007; Murphy \& Jerome, 2005). However, neither of the studies report whether the ability to identify these patterns led to subsequent changes in chat quality (Kayler \& Weller, 2007; Murphy \& Jerome, 2005).

Our quantitative results support the findings of De Wever et al. (2008) and suggest that the addition of self-reflections to a chat format, even if thoughtfully completed by students as indicated by our qualitative results, is not sufficient to cause students to increase their critical thinking or interaction with other students in online chats. Both studies consider an undergraduate-level course. We therefore echo earlier calls for further research on the effects of providing training for undergraduates prior to completing self-assessments (De Wever et al., 2008). We also suggest that future work could look into whether changing the focus of the self-reflection to emphasize the desired pedagogical outcomes or adding a step to make the self-reflection salient immediately before the subsequent chat could result in a stronger quantifiable effect from the self-reflection intervention.

\section{Group Reflections}

For both Chat 3 and Chat 4, groups that completed group reflections wrote a greater proportion of higher level thinking posts than groups that did not complete group reflections. This difference was significant for Chat 3 . This suggests that, in this case, providing groups an opportunity to discuss what happened in a chat and collectively decide on steps to improve the chat quality may have helped them maintain higher level thinking throughout the semester and sustain thoughtful discussion outside the framework of assigned roles. Furthermore, these results offer evidence that self-reflections and roles, which were implemented identically for all groups for Chats 2 through 4, were not enough on their own to sustain higher level thinking in chats throughout the semester.

In our qualitative analysis, among the three groups analyzed, one group, Group A, possessed unique qualities. This group demonstrated more agency than the other two groups and more frequently suggested concrete changes to address inadequacies they saw in the chats. We suggest the following relationship between these two observations: If Group A felt empowered to solve their own problems, they may have been more likely to suggest concrete actions to take in solving these problems. Previous work has shown that students who feel agency in online chats generally have a more positive chat experience (Kayler \& Weller, 2007). We suggest future work should investigate whether feeling agency over the chat may also translate into students being able to suggest practical actions for improving ineffective aspects of the chat.

Even though Group A was successful in identifying aspects of the chat under their control that were ineffective and subsequently proposed concrete actions to effect change, the group had mixed success in implementing these actions in the following chat. The group was able to implement the suggestion that they focus on one topic at a time and discussed this in the subsequent reflection as a successful achievement and improvement in chat quality. However, there was a 
notable instance where some individuals from the group attempted to try the hand-raise feature included in the chat software, which was agreed upon by many during the group reflection, but the idea was rejected when proposed during the chat. This case reflects many of the top frustrations expressed by students completing online group work - namely, unshared goals, communication difficulties, and negotiation problems (Capdeferro \& Romero, 2012). In future group reflection activities, it seems essential that the group be given more of a framework for successful group work (Capdeferro \& Romero, 2012), including reaching buy in from all group members.

The final theme that emerged was that the deficiencies identified in the chats tended to focus on logistics over outcomes. There are a couple possible explanations for the focus on these logistical issues. First, it seems evident that the chat format, specifically, the "rush" created by the synchronous posting, was not satisfactory and was seen by students as inhibiting their ability to have an effective chat. The volume of posts in online discussions has been previously found to overwhelm students and lead them to feel lost in the conversation (Basharina, 2009). Second, the group-reflection prompt did not explicitly instruct students to focus on the pedagogical outcomes of higher order thinking and questioning; therefore, it seems reasonable that students would not choose to focus on these aspects. An alternative definition of the discussion roles could help shift the focus more to learning outcomes than specific logistical processes (i.e., give direction, ask questions, summarize). These new roles could be called the Information Explorer, Information Integrator, and Resolution Finder, informed by the goals of deep learning outlined by (Garrison \& Cleveland-Innes, 2005).

\section{Recommendations}

Based on the results of this study, we plan to make the following changes in the next semester of this course and suggest these modifications also be tested by others looking to implement process-oriented roles and group reflections in online learning courses featuring synchronous discussions:

- For process-oriented roles, focus the definition on one specific function, rather than wrapping multiple functions into a role, to enhance fulfillment of target functions, such as "synthesize" and "critique."

- Remove self-reflections from the course assignments.

- Change the group-reflection activity to ask students to (1) focus on the desired learning outcomes and (2) reach a consensus and get buy in from whole group.

While our study has the limitation of being a case study of a single course, we feel some aspects of our results can be applied more generally. We add to the body of literature demonstrating that roles help engage students in chats (e.g., Wise et al., 2012), especially with their peers (e.g., Hara et al., 2000); however, our research highlights concerns that are specific to synchronous chats when designing role descriptions. Specifically, the fast-paced nature of the chat might cause students to need the logistical functions in the roles simply to have a manageable discussion. Our research also explores the relatively undocumented process of group reflections in online settings and provides several guidelines for improving the group-reflection process. We feel groupreflection assignments could allow for increased student autonomy in running online discussion and agency in achieving the pedagogical goals for the course. Future work should investigate the effects of our suggested changes to process-oriented role definitions and group-reflection activities in online classes of varying sizes and topical content. 


\section{References}

Allen, I. E., \& Seaman, J. (2016). Online report card: Tracking online education in the United States. Babson Survey Group. Retrieved from https://onlinelearningconsortium.org/read/online-report-card-tracking-online-educationunited-states-2015/

Basharina, O. (2009). Student agency and language-learning processes and outcomes in international online environments. CALICO Journal, 26(2), 390-412. https://doi.org/10.1558/cj.v26i2.390-412

Bernard, R. M., Abrami, P. C., Borokhovski, E., Wade, C. A., Tamim, R. M., Surkes, M. A., \& Bethel, E. C. (2009). A meta-analysis of three types of interaction treatments in distance education. Review of Educational Research, 79(3), 1243-1289. https://doi.org/10.3102/0034654309333844

Bloom, B. S., Engelhart, M. D., Furst, E. J., Hill, W. H., \& Krathwohl, D. R. (1956). Taxonomy of educational objectives, handbook I: The cognitive domain. New York: David McKay Co Inc.

Bradley, M. E., Thom, L. R., Hayes, J., \& Hay, C. (2008). Ask and you will receive: How question type influences quantity and quality of online discussions. British Journal of Educational Technology, 39(5), 888-900. https://doi.org/10.1111/j.1467$\underline{8535.2007 .00804 . \mathrm{x}}$

Capdeferro, N., \& Romero, M. (2012). Are online learners frustrated with collaborative learning experiences? The International Review of Research in Open and Distributed Learning, 13(2), 26-44. http://dx.doi.org/10.19173/irrodl.v13i2.1127

De Wever, B., Schellens, T., Van Keer, H., \& Valcke, M. (2008). Structuring asynchronous discussion groups by introducing roles: Do students act in line with assigned roles? Small Group Research, 39(6), 770-794. https://doi.org/10.1177/1046496408323227

De Wever, B., Van Keer, H., Schellens, T., \& Valcke, M. (2007). Applying multilevel modelling to content analysis data: Methodological issues in the study of role assignment in asynchronous discussion groups. Learning and Instruction, 17(4), 436-447. https://doi.org/10.1016/j.learninstruc.2007.04.001

Ertmer, P. A., Sadaf, A., \& Ertmer, D. J. (2011). Student-content interactions in online courses: The role of question prompts in facilitating higher-level engagement with course content. Journal of Computing in Higher Education, 23(2-3), 157-186. https://doi.org/10.1007/s12528-011-9047-6

Garrison, D. R., \& Cleveland-Innes, M. (2005). Facilitating cognitive presence in online learning: Interaction is not enough. The American Journal of Distance Education, 19(3), 133-148. https://doi.org/10.1207/s15389286ajde1903_2

Gibbs, G. (1994). Learning in teams. Oxford: Oxford Centre for Staff Development.

Gibbs, G. (2012). Grounded theory, coding and computer-assisted analysis. In Understanding research for social policy and social work: Themes, methods and approaches (2nd ed., pp. 337-343). Bristol: Policy Press. 
Hara, N., Bonk, C. J., \& Angeli, C. (2000). Content analysis of online discussion in an applied educational psychology course. Instructional Science, 28(2), 115-152. https://doi.org/10.1023/A:1003764722829

Holden, J. T., \& Westfall, P. J.-L. (2007). An instructional media selection guide for distance learning (4th ed.). Retrieved from http://eric.ed.gov/?id=ED501248

Kayler, M., \& Weller, K. (2007). Pedagogy, self-assessment, and online discussion groups. Educational Technology \& Society, 10(1), 136-147. Retrieved from https://eric.ed.gov/?id=EJ814021

Lindgren, R., \& McDaniel, R. (2012). Transforming online learning through narrative and student agency. International Forum of Educational Technology \& Society, 15(4), 344 355. Retrieved from https://eric.ed.gov/?id=EJ992968

Martin, F., Ahlgrim-Delzell, L., \& Budhrani, K. (2017). Systematic review of two decades (1995 to 2014) of research on synchronous online learning. American Journal of Distance Education, 31(1), 3-19. https://doi.org/10.1080/08923647.2017.1264807

Mercer, N., Wegerif, R., \& Dawes, L. (1999). Children's talk and the development of reasoning in the classroom. British Educational Research Journal, 25(1), 95-111. https://doi.org/10.1080/0141192990250107

Moore, M. G. (1989). Editorial: Three types of interaction. American Journal of Distance Education, 3(2), 1-7. https://doi.org/10.1080/08923648909526659

Murphy, E., \& Jerome, T. (2005). Assessing students' contributions to online asynchronous discussions in university-level courses. Electronic Journal of Instructional Science and Technology, 8. Retrieved from http://ascilite.org/archived-journals/ejist/docs/vol8 nol/commentary/stu_contrib_ansynch.htm

Parker, K., Lenhart, A., \& Moore, K. (2011). The digital revolution and higher education: College presidents, public differ on value of online learning. Pew Internet \& American Life Project. Retrieved from http://eric.ed.gov/?id=ED524306

Pear, J. J., Crone-Todd, D. E., Wirth, K. M., \& Simister, H. D. (2001). Assessment of thinking levels in students' answers. Academic Exchange Quarterly, 5(4), 94-99.

Persell, C. H. (2004). Using focused web-based discussions to enhance student engagement and deep understanding. Teaching Sociology, 32(1), 61-78. http://www.jstor.org/stable/3211348

R Core Team. (2015). R: A language and environment for statistical computing. Vienna, Austria: R Foundation for Statistical Computing. Retrieved from https://www.r-project.org/

Schellens, T. (2005). The impact of role assignment on knowledge construction in asynchronous discussion groups: A multilevel analysis. Small Group Research, 36(6), 704-745. https://doi.org/10.1177/1046496405281771

Schellens, T., Van Keer, H., De Wever, B., \& Valcke, M. (2007). Scripting by assigning roles: Does it improve knowledge construction in asynchronous discussion groups? International Journal of Computer-Supported Collaborative Learning, 2(2-3), 225-246. https://doi.org/10.1007/s11412-007-9016-2 
Sengupta, S. (2001). Exchanging ideas with peers in network-based classrooms: An aid or a pain? Language Learning \& Technology, 5(1), 103-134. Retrieved from https://eric.ed.gov/?id=EJ621505

Sogunro, O. A. (2002). Selecting a quantitative or qualitative research methodology: An experience. Educational Research Quarterly; West Monroe, 26(1), 3. Retrieved from https://search.proquest.com/docview/216183188?accountid=10267

Strijbos, J.-W., Martens, R. L., Jochems, W. M. G., \& Broers, N. J. (2007). The effect of functional roles on perceived group efficiency during computer-supported collaborative learning: a matter of triangulation. Computers in Human Behavior, 23(1), 353-380. https://doi.org/10.1016/j.chb.2004.10.016

Sun, A., \& Chen, X. (2016). Online education and its effective practice: A research review. Journal of Information Technology Education: Research, 15, 157-190. Retrieved from https://eric.ed.gov/?id=EJ1103754

Tagg, A. C. (1994). Leadership from within: Student moderation of computer conferences. American Journal of Distance Education, 8(3), 40-50. https://doi.org/10.1080/08923649409526865

Tukey, J. W. (1977). Exploratory data analysis.

Walker, S. A. (2004). Socratic strategies and devil's advocacy in synchronous CMC debate. Journal of Computer Assisted Learning, 20(3), 172-182. Retrieved from https://eric.ed.gov/?id=EJ686077

Ware, P. (2005). "Missed" communication in online communication: Tensions in a GermanAmerican telecollaboration. Language Learning \& Technology, 9(2), 64-89. Retrieved from https://eric.ed.gov/?id=EJ846321

Williams, K. M. (2015). Doing research to improve teaching and learning. Taylor \& Francis.

Wise, A. F., \& Chiu, M. M. (2011). Analyzing temporal patterns of knowledge construction in a role-based online discussion. International Journal of Computer-Supported Collaborative Learning, 6(3), 445-470. Retrieved from https://doi.org/10.1007/s11412-011-9120-1

Wise, A. F., Saghafian, M., \& Padmanabhan, P. (2012). Towards more precise design guidance: Specifying and testing the functions of assigned student roles in online discussions. Educational Technology Research and Development, 60(1), 55-82. https://doi.org/10.1007/s11423-011-9212-7

Zhu, E. (1998). Learning and mentoring: Electronic discussion in a distance-learning course. In Electronic collaborators: Learner-centered technologies for literacy, apprenticeship, and discourse (pp. 233-257). New York, NY: Routledge. 


\section{Appendix A}

\section{SELF REFLECTION WORKSHEET}

NAME:

CHAT NUMBER:

WHAT ROLE DID YOU PLAY?:

\section{TRAFFIC DIRECTOR}

1. Provide a quote from the chat (no name unless this was the role you played) that demonstrates a time when this role was successfully played.

2. What was the result of the Traffic Director's action, and how did it improve the discussion?

3. Provide a quote from the chat (no name unless this was the role you played) that demonstrates a time when this role could have been better played, or was totally missing from the discussion.

4. What could the Traffic Director have done differently in this example? How would this different action have changed the discussion for the better?

\section{QUESTIONER}

1. Provide a quote from the chat (no name unless this was the role you played) that demonstrates a time when this role was successfully played.

2. What was the result of the Questioner's action, and how did it improve the discussion? 
3. Provide a quote from the chat (no name unless this was the role you played) that demonstrates a time when this role could have been better played, or was totally missing from the discussion.

4. What could the Questioner have done differently in this example? How would this different action have changed the discussion for the better?

\section{SYNTHESIZER}

1. Provide a quote from the chat (no name unless this was the role you played) that demonstrates a time when this role was successfully played.

2. What was the result of the Synthesizer's action, and how did it improve the discussion?

3. Provide a quote from the chat (no name unless this was the role you played) that demonstrates a time when this role could have been better played, or was totally missing from the discussion.

4. What could the Synthesizer have done differently in this example? How would this different action have changed the discussion for the better? 


\section{Appendix B}

\section{ABBREVIATED SELF-REFLECTION WORKSHEET}

NAME:

WHAT ROLE DID YOU PLAY?:

1. Provide a specific example (quote or concise summary of exchanges) from the chat where you feel you made a good contribution, and describe specifically how your contribution helped the discussion. Keep the three chat roles in mind, especially the one you were assigned.

2. In which of the three chat roles do you think you have the most room for improvement? Provide a specific example from the current chat of where you could practice this role in the future, and describe what action your future self would take. How would this action help the discussion? 


\section{Appendix C}

In this discussion forum, you will complete a group reflection on your chat. Why do a group reflection on your chat? Because effective team work and effective conversation results when everyone is on the same page about expectations and goals. The only way this can be achieved is having everyone in the group discuss these expectations and goals. After the debate, your TA will post a transcript to the "Chat 2" thread in the "Chats" discussion forum for your discussion group. Please reference this transcript when completing this assignment.

For your first post in your group reflection forum, fill in the following two sentences:

The most effective thing about our group's chat was..... because.....

The most ineffective thing about our group's chat was.....because.....

Your initial post is due by 6pm on Tuesday, Nov 1 st.

You are expected to read through all the initial posts of your group members. Then, participate in a discussion that synthesizes these posts into key actions your group should take in the next chat. For example, by the end of the discussion, your group should come to conclusions along the lines of:

Next time, our group should continue.....because.....

Next time, our group should start/stop/change.....because.....

We are not looking for a specific number of replies in this forum. Rather, we are interested in your ability to synthesize what is being said and be responsive to your group-mates.

Your replies in the group discussion forum are due by $6 \mathrm{pm}$ on Thursday, Nov 3rd. Please review the attached rubric to see how you will be graded. 